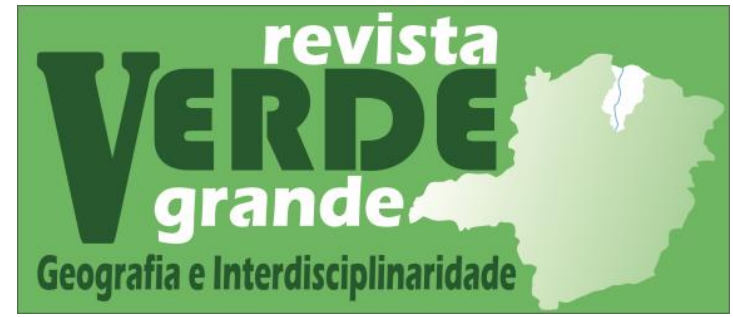

Volume 2, no. 2 (2020)

ISSN: 2675-2395

https://doi.org/10.46551/rvg2675239520202146149

\title{
RESENHA
}

\section{A CRUEL PEDAGOGIA DO VÍRUS}

Bruna França Oliveira ${ }^{1}$ https://orcid.org/0000-0001-8987-510X

\footnotetext{
${ }^{1}$ Graduanda em Geografia - Universidade Estadual de Montes Claros, Bolsista BIC-UNI. E-mail: brunaolifr@gmail.com
}

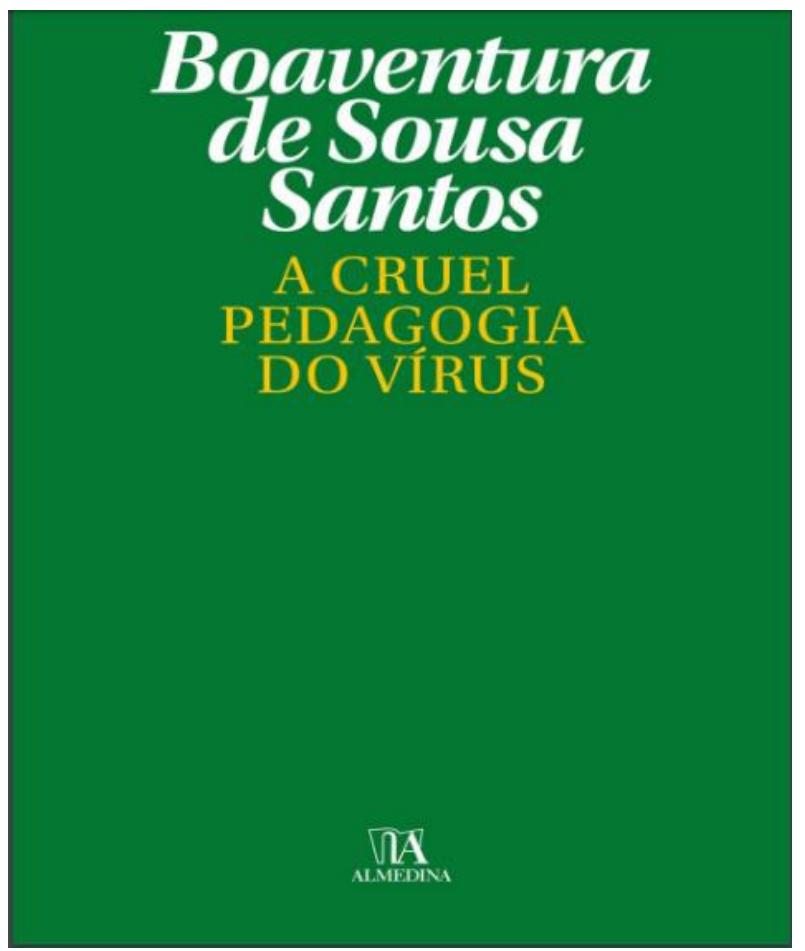

A então Pandemia do novo coronavírus, denominado cientificamente de SARS-CoV-2, provocou diversos impactos sobre as sociedades do mundo inteiro em seus aspectos políticos, econômicos e sociais. Dessa forma, o sociólogo Boaventura de Sousa Santos² em seu texto “A Cruel Pedagogia do Vírus” irá suscitar o debate acerca dos impactos da pandemia evidenciando, sobretudo, a ineficiência do sistema econômico e financeiro vigente somada a fragilidade do Estados em respostas as diversas mazelas da sociedade se acentuam em momentos de crise.

\footnotetext{
2 Influente sociológo da língua portuguesa atualmente, é professor Catedrático Jubilado da Faculdade de Economia da Universidade de Coimbra e Distinguished Legal Scholar da Faculdade de Direito da Universidade de Wisconsin-Madison e Global Legal Scholar da Universidade de Warwick. É igualmente Director Emérito do Centro de Estudos Sociais da Universidade de Coimbra e Coordenador Científico do Observatório Permanente da Justiça. Bibliográfia completa disponivel em: <http://www.boaventuradesousasantos.pt/pages/pt/homepage.php $>$. Acesso em: 10 jul. 2020.
} 


\section{Resenha - A Cruel Pedagogia do Vírus (2020)}

Bruna França Oliveira

O trabalho é dividido em cinco sucintos capítulos no qual o primeiro "Vírus: tudo o que é sólido se desfaz no ar" o autor discorre sobre os potenciais conhecimentos que podem decorrer da pandemia do coronavírus. Santos elenca alguns pontos, primeiramente, que a pandemia não é uma situação de crise frente à normalidade, o que o autor chama de "a normalidade da exceção". Desde a década de 1980, com a ascensão do neoliberalismo no sistema financeiro vigente estamos vivenciando uma atípica crise.

Como explica Santos, ao contrário do sentindo etimológico que a palavra crise traz de situação passageira e superável esta é permanente, ainda é a "causa que explica tudo o resto" (s/n). Apresenta-se pelos cortes em políticas sociais, como saúde, educação e previdência social, fincando a pandemia do coronavírus como uma agravante da condição de crise que a população mundial já passa.

A elasticidade social também aponta para a crise do sistema capitalista a medida que durante o momento de pandemia é possível pensar novas alternativas de vida, consumo e produção que supere o modelo vigente pautado no capitalismo. A questão da catástrofe ecológica mundial que enfrentamos se junta nesse mesmo sentido. Defende o Estado democrático, e seu papel no controle da pandemia, onde, mesmo sendo sujeitos as atuais fake news, são estes que tendem a serem menos afetados pelas epidemias, dado a rapidez da circulação de informações que habilita a população para se proteger do vírus, logo, prevenir que este se propague.

Ressalta a guerra invisível existente durante a pandemia, uma guerra comercial entre duas grandes nações, EUA vs China. Esta recai no modo como os meios de comunicação ocidentais abordam o contexto culpabilizando a China, deixando a segunda maior potência econômica mundial como incapaz de controlar danos à saúde mundial. No que se refere a comoção mundial, a pandemia é o momento em que surge um sentimento de comunhão planetária dado a insegurança que ela produz, simultaneamente, também é formado as zonas de invisibilidade frente a diversos problemas, como exemplificado por Santos a situação em que os refugiados na Europa se encontram.

No segundo capítulo intitulado "A trágica transparência do vírus" Santos trata a forma como a pandemia do coronavírus elucida a situação de grande parte da população da qual na maioria das vezes é ignorada mesmo pelo Estado, que prefere atender as necessidades e aspirações do mercado. O autor utiliza de alegorias para ilustrar a sujeição da sociedade para com o mercado, que atua promovendo a ascensão social para alguns em detrimento de muitos. Como também pelo que o autor chama dos "três unicórnios", ou seja, três doutrinas, as quais são: capitalismo, colonialismo e patriarcalismo, que sustenta as desigualdades sociais existentes.

De acordo com Santos esses sistemas se mantem desde o século XVII através de diferentes estratégias. Como a de desaparecer quando continuam vivos, como é o caso do capitalismo que está presente e controla mesmo na China comunista, ou o colonialismo que se transfigurou no neocolonialismo, imperialismo, dependência, racismo. Ainda parecer fracos quando permanecem fortes como o patriarcado onde os índices da violência doméstica, a discriminação sexista e o feminicídio aumentam concomitante aos movimentos feministas.

Outra estratégia é utilizar da ideia de que representam entidades separadas quando na verdade consistem em uma só. Diante deste quadro dois cenários se apresentam atualmente: da intensa desigualdade social e o da catástrofe ecológica. Santos destaca, ainda, a dificuldade de teorização deste momento tão caótico e a urgência 


\section{Resenha - A Cruel Pedagogia do Vírus (2020)}

Bruna França Oliveira

do que o autor chama de intelectuais de retaguarda, aqueles que estão atentos e teorizam a partir das necessidades e aspirações dos cidadãos comuns.

No capítulo 3 “A sul da quarentena” traz a perspectiva discriminatória da pandemia, assim, este capítulo irá apresentar os grupos que mais sofrerão neste momento, em função de questões sanitárias que não foram resolvidas, como saneamento básico, habitação e educação. Santos denomina estes grupos como Sul, não se referindo ao sul do espaço geográfico, mas sim nos aspectos espaço-tempo político, social e cultural. Dessa forma, o autor aponta alguns grupos, como as mulheres que, sendo maioria consideradas cuidadoras terão que garantir a quarentena de outros grupos em detrimento da sua, dentro de casa poderá ter-se o aumento do stress dado as tarefas domésticas, mas, principalmente, sofrerão com o aumento da violência, como é comum ocorrer em momentos de guerra e crise.

A quarentena também será difícil para os trabalhadores informais, autônomos e de rua dado a precarização das condições e dos direitos dos trabalhadores, esta última por parte da atuação das políticas neoliberais. Para estes trabalhadores o trabalho em casa é impraticável, além de alguns precisarem da rua e de gente nela, assim, seguir as recomendações da OMS não é uma opção, uma vez que, precisam garantir o sustento da família.

Do mesmo modo para as populações de rua e moradores de periferias, como será a quarentena para quem não tem casa ou para quem a habitação não é adequada? Especialmente para os moradores de periferias, Santos aponta que surgem algumas emergências, como emergência a sanitária, a emergência a alimentar, a emergência da violência doméstica e policial.

A lista cresce quando pensamos nas condições dos refugiados, como já citado, de deficientes físicos, idosos, presos e pessoas com problemas de saúde mental. Dessa maneira percebe-se que a quarentena reforça a injustiça, a discriminação e a exclusão social mesmo quando torna estes grupos mais visíveis na sociedade, fomentando comportamentos individualistas.

No capítulo 4 "A intensa pedagogia do vírus: as primeiras lições" indica ensinamentos da atual crise. Dado o caráter grave a agudo da crise da pandemia esta mobiliza a mídia e a política mais ativa e dramaticamente quanto outras crises que estamos enfrentando. Como é o caso da crise ambiental que apresenta grandes impactos, porém de forma mais lenta por isso tendem a passar despercebida. Santos ressalta que a pandemia pode ser revertida, ao contrário da crise ambiental que já é irreversível.

A crise da pandemia também é discriminatória no que se refere a sua prevenção e expansão, pois diversos grupos, como colocado no capítulo anterior, não são capazes de cumprir as recomendações da OMS ficando mais vulneráveis que outros. Santos completa, ainda, defendendo que este é um momento de fortalecimento do colonialismo e patriarcado. Durante a crise a vulnerabilidade de grupos discriminados racial e sexualmente aumenta, devido sua exposição a condições precárias de habitação, trabalho, entre outros.

O capitalismo no seu modelo mais recente, o neoliberalismo, mesmo que continue como modelo de produção, distribuição e consumo, não deve conduzir a atuação do Estado e da sociedade, como vem ocorrendo. $\mathrm{O}$ princípio dos mercados tornou-se nos últimos quarenta anos prioridade, sujeitando áreas importantes da sociedade, como saúde, educação, e segurança social a lógica do capital. Tal enfraquecimento da atuação do Estado o deixou incapacitado para reagir de forma eficiente frente a crises humanitárias, como a que estamos passando. 
O autor salienta que na atual crise os governos voltados para os ideais de direita e neoliberalismo foram os menos eficazes no controle do coronavírus, pois priorizaram salvar a economia a minimizar os efeitos da pandemia. Em contrapartida os países menos fiéis aos ideais neoliberais tomaram ações mais eficientes contra o coronavírus.

Por fim, no capítulo 5 "O futuro pode começar hoje" Santos sugere uma nova forma de organização da sociedade que supere a forma de viver, consumir e produzir vigente pautada no capitalismo. Segundo o autor, continuar no mesmo modelo sujeita a sociedade a ficar vulnerável a novas pandemias e desastres ambientais. Para tanto, Santos propõe pôr fim a separação entre processos políticos e processos civilizatórios que se deu simbolicamente com a queda do muro de Berlim. A partir de tal acontecimento estabelece a ideia de que não há alternativas ao capitalismo e a tudo que ele provoca.

A articulação entre processos políticos e processos civilizatórios também é desfeita nesse momento, passando os processos políticos passaram a se envolver na gestão do capitalismo e seus desdobramentos, enquanto os processos civilizatórios continuaram acontecendo, porém fora dos processos políticos. A rearticulação destes implica em uma viragem epistemológica, cultural e ideológica onde se poderia pensar uma sociedade mais humilde e menos dependente do consumo e entretenimento fúteis. Igualmente unida a partir de um consenso que permite considerar a Terra como a casa comum de todos os seres vivos e não vivos, e a qual devemos mais respeito.

\section{Referências}

SANTOS, Boaventura de Sousa. A Cruel Pedagogia do Vírus. Coimbra: Edições Almedina, 2020. 32p. Disponível em: 〈https://www.cpalsocial.org/documentos/927.pdf>. Acesso em: 01. Jun. 2020. 